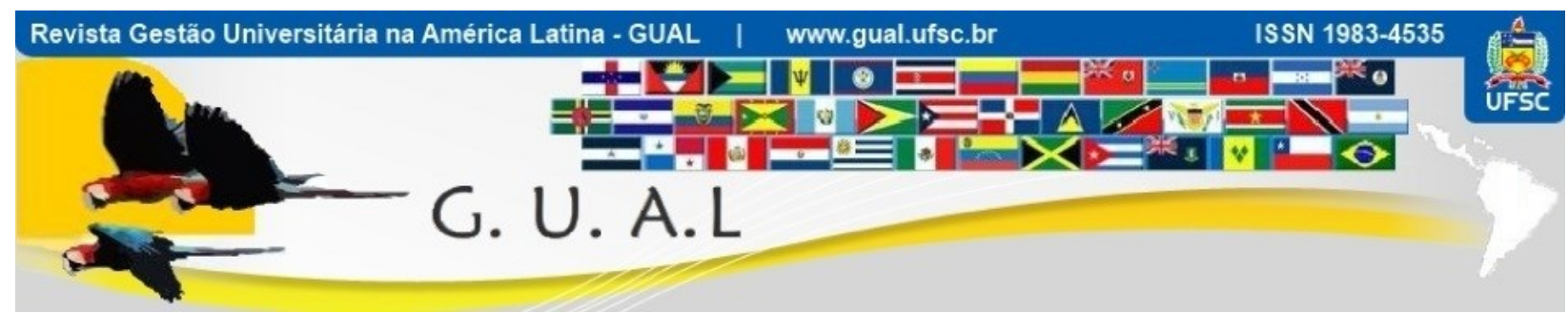

DOI: http://dx.doi.org/10.5007/1983-4535.2015v8n3p161

\title{
CULTURA ORGANIZACIONAL E MUDANÇAS NA GESTÃO DA FACULDADE MUNICIPAL DE PALHOÇA
}

\section{ORGANIZATIONAL CULTURE AND CHANGE MANAGEMENT OF MUNICIPAL COLLEGE PALHOÇA}

Joici Lilian Rodrigues, Mestre Faculdade Municipal de Palhoça - FMP joicililian@hotmail.com

Flávio Ramos, Doutor Universidade do Vale do Itajaí - UNIVALI

flauni@univali.br

Karini Regina Homem, Mestranda Universidade do Sul de Santa Catarina - UNISUL kareho@hotmail.com

Mariah Terezinha Nascimento Pereira, Mestre Faculdade Municipal de Palhoça - FMP mariahnascimento@terra.com.br

Fábio Henrique Pereira, Mestre Faculdade Municipal de Palhoça - FMP professorfabio@outlook.com

Recebido em 24/julho/2014

Aprovado em 11/junho/2015

Sistema de Avaliação: Double Blind Review

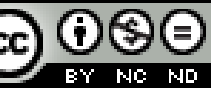

Esta obra está sob uma Licença Creative Commons Atribuição-Uso. 


\title{
CULTURA ORGANIZACIONAL E MUDANÇAS NA GESTÃO DA FACULDADE MUNICIPAL DE

\section{RESUMO}

Este artigo se propôs analisar as percepções dos gestores da instituição que representam o esboço do que pode ser compreendido como aspectos da cultura organizacional da Faculdade Municipal de Palhoça. Teve como objetivos específicos: a) pontuar aspectos da cultura organizacional da instituição; b) identificar valores do grupo de gestores; c) relacionar as diferentes percepções dos gestores com relação às políticas públicas no Município e às possibilidades, na perspectiva desses gestores, de interpretar a cultura da Faculdade Municipal de Palhoça. O estudo foi feito a partir da metodologia exploratória, onde o agente pesquisador interpreta a coleta de dados de cunho qualitativo, utilizando análise de discurso. A pesquisa se refere a um estudo de caso interpretativo em uma instituição pública municipal no qual foi aplicado o instrumento de entrevista com roteiro semiestruturado como técnica de coleta de dados, auferindo dados primários, partindo do paradigma interpretativista. As entrevistas foram realizadas no período de outubro/2013 com os diretores, coordenadores de graduação e pós-graduação. Após a discussão teórica e empírica sobre o tema cultura e mudança organizacional, o objetivo da analise contida no trabalho foi entender o fenômeno organizacional e o comportamento dos atores inseridos no contexto de uma instituição pública de educação superior da Grande Florianópolis.

Palavras-chave: Percepções dos gestores. Cultura organizacional. Mudança organizacional.

\begin{abstract}
This dissertation analyzes the perceptions of managers of the Faculdade Municipal de Palhoça, which represent an outline of what can be understood as aspects of the organizational culture of this educational institution. Its specific objectives are: a) to indicate aspects of the organizational culture of the institution; b) to identify values among the group managers; c) to link the different perceptions of managers to the public policies of the Municipality, and to the possibilities, in the managers' perception, of interpreting the culture of the Faculdade Municipal de Palhoça. The study was conducted using the exploratory method, in which the researcher agent interprets the data collection using a qualitative approach, with discourse analysis. The survey is an interpretative case study of a municipal institution, in which a semistructured interview was applied as the data collection technique, which provided primary data, based on the interpretive paradigm. The interviews were conducted in October 2013, with the directors, and undergraduate and postgraduate coordinators. Following a theoretical and empirical discussion on the theme of organizational culture and change, the objective of analysis of the study was to understand the organizational phenomena and behavior of actors within the context of a public higher education institution in Greater Florianópolis.
\end{abstract}

Keywords: Perceptions of the managers. Organizational culture. Organizational change. 


\section{CULTURA ORGANIZACIONAL E MUDANÇAS NA GESTÃO DA FACULDADE MUNICIPAL DE

\section{INTRODUÇÃO}

A cultura exerce influência no comportamento humano e não moldam somente os conjuntos heterogêneos dos agrupamentos sociais. A pluralidade cultural pode concomitantemente convier no mesmo grupo. A cultura organizacional no decorrer dos anos vem ganhando uma importante posição dentro das organizações, podemos apontar o termo cultura organizacional como assunto de total relevância na atualidade, no que concerne o estudo sobe o comportamento humano no arranjo organizacional, visto que os princípios básicos são partilhados pelo grupo social, tendo influência no modo que os membros das organizações sentem, pensam e agem (SILVA; ZANELLI, 2004).

Toda organização tem sua própria cultura que a diferencia formando um conjunto que realça os seus costumes, seus valores e suas crenças. A cultura organizacional é definida de maneira sistemática com princípios compartilhados que nasce e se amplia dentro das organizações e conduz a direção de seus membros. Essa característica contextualiza as diferentes definições da organização a respeito do papel dos seus membros no cotidiano (SCHERMERHORN,1999).

A cultura organizacional representa o agregado de crenças, princípios onde a natureza dos trabalhos e, portanto das suas ligações que difere de uma organização para a outra. A cultura pode influenciar a personalidade de uma organização consequentemente o caráter atestado pelos próprios funcionários das organizações (LUZ, 2003).

Observa-se que a cultura organizacional movimenta o dia-a-dia da organização, suas decisões, as atribuições de seus funcionários, as formas de recompensas e punições, as maneiras de relacionamento com os seus parceiros comerciais, seus móveis, o tipo de liderança adotado, o processo de comunicação, a forma de vestir e de portar-se dos funcionários no ambiente de trabalho, sua propaganda e, assim, por diante.

O funcionário, no primeiro momento, entra na organização com valores determinados pela escola, família, sociedade e até mesmo por alguma organização que já tenha feito parte. Devemos levar em consideração a construção desses sujeitos sociais que compõe os arranjos organizacionais como procedência étnica, regionais, geográficas, culturais, condição sexual, formação profissional isto é toda a sua história (JAIME JÚNIOR, 2002).

O desafio que o gestor moderno enfrenta é interpretar os diferentes mundos sociais da empresa, para que se consiga perceber novas maneiras de contemplar, interpretar e posteriormente adaptar as situações com as quais tem de lidar. Isso não impede, muitas vezes, 


\section{CULTURA ORGANIZACIONAL E MUDANÇAS NA GESTÃO DA FACULDADE MUNICIPAL DE

que valores sejam internalizados a partir das ações dos gestores, ou seja, a alta administração pode, efetivamente, forçar determinados comportamentos no ambiente organizacional.

A metodologia utilizada será do tipo qualitativa, tendo como características observar a instituição internamente, compreender a situação em um contexto geral e destacar os acontecimentos ao longo do tempo de existência da instituição.

\section{CULTURA ORGANIZACIONAL}

Quando as pessoas agem de acordo com as expectativas de outras, o seu comportamento é eminentemente social. As pessoas nascem, crescem, vivem e se comportam em um ambiente social e dele recebem uma complexa e continua influência no decorrer de toda a sua vida. A cultura representa o ambiente de crença e valores, costumes, tradições, conhecimentos e práticas de convívio social e relacionamento entre as pessoas. A cultura significa um comportamento convencional aceito pela sociedade e provoca enorme influência e condicionamento sobre todas as ações e comportamentos das pessoas (FREITAS, 2000).

Ainda conforme a mesma autora, a cultura consiste em padrões explícitos e implícitos de comportamentos adquiridos e transmitidos ao longo do tempo e que constitui uma característica própria de cada sociedade. Numa perspectiva funcionalista, é por meio da cultura que a sociedade impõe expectativas e normas de conduta sobre seus membros e condiciona-os a se comportarem de maneira socialmente aceitável aos seus padrões, crenças, valores, costumes e práticas sociais.

A cultura é um fenômeno dinâmico que nos cerca a todo momento. Conforme Schein (2009), ela é constantemente desempenhada e criada por nossas interações com outros e moldada por comportamento de liderança, em um conjunto de rotinas, regras e normas que orientam e restringem o comportamento. Esse processo de criação e gerenciamento da cultura são a essência da liderança e nos faz perceber que cultura e liderança constituem dois lados da mesma moeda.

As organizações devem ter a ciência de que a sua cultura tem papel fundamental para o andamento do processo organizacional, podendo proporcionar um ritmo a ser seguido por parte se seus trabalhadores. A cultura organizacional é fundamentalmente um arranjo de princípios que orienta as ações de uma organização (FREITAS, 2007).

A cultura é um dos pontos chave na compreensão das ações humanas, funcionando como uma referência coletiva que identifica os grupos, suas maneiras de perceber, pensar, 


\section{CULTURA ORGANIZACIONAL E MUDANÇAS NA GESTÃO DA FACULDADE MUNICIPAL DE

sentir e agir. Assim, mais do que um conjunto de regras, de hábitos e de artefatos, cultura significa construção de significados partilhados pelo conjunto de pessoas pertencentes a um mesmo grupo social (PIRES; MACEDO, 2006).

A cultura das organizações também se baseia nos valores culturais da sociedade inserida. Devemos associar a cultura organizacional com a cultura nacional, pois não há entidade isolada do ambiente externo (LUZ, 2003; HOFSTEDE, 1998).

A cultura influencia no comportamento de todos os indivíduos e grupos da organização. Impactando no cotidiano, atuando nas decisões, atributos dos funcionários, nas formas de recompensas e punições, no estilo de liderança adotado, na comunicação, na forma como os funcionários se vestem e se portam no ambiente de trabalho, e assim por diante. (LUZ, 2003).

Com isso, as organizações interagem com o ambiente em que estão imersas, recebendo influências e influenciando-o. Desta maneira, os trabalhadores são os agentes que cooperam para que ocorra essa troca constante, sendo os seus valores e crenças componentes para o desenvolvimento da cultura organizacional (PIRES; MACÊDO, 2006).

Em concordância com o autor supracitado, pode-se falar que todo funcionário conduz a organização uma associação de generalidades de sua vivência anterior, criando assim uma simbiose com a vivência dos demais membros. O sujeito traz para o trabalho sua carga de fenômenos emocionais, parte de como ele vê e está inserido no mundo e essa bagagem é muito difícil de ser desfeita (FIORELLI, 2000).

No entendimento de Dubrin (2006), dependendo da intensidade de sua força, a cultura organizacional de uma organização pode gerar um impacto na busca do alcance dos objetivos. Em uma organização, onde a cultura organizacional é forte, os funcionários seguem seus valores sem questionamentos. Porém em uma cultura mais fraca, serve apenas de diretrizes, pois a cultura não tem muita influência sobre a organização.

Portanto, quanto mais sólida for à base da cultura organizacional menor será a sua afetação aos grupos das culturas heterogêneas com uma cultura maior (ZANELLI, BORGESANDRADE; BASTOS, 2004). Desta forma, é essencial que o gestor repasse informações sobre a cultura organizacional da instituição, pois assim poderá evitar futuros conflitos internos na instituição.

A cultura organizacional pode ser mantida ou até transformada, porém precisa-se ter consciência para identificar o que e como mudar quando preciso. Sendo necessário 


\section{CULTURA ORGANIZACIONAL E MUDANÇAS NA GESTÃO DA FACULDADE MUNICIPAL DE

compreender o que pode e o que não pode ser feito, seguindo as normas ou estratégias da administração, por meio do conhecimento dos princípios e valores (LACOMBE, 2005). O esforço empregado para realizar uma mudança na cultura organizacional deve focar nas tarefas rotineiras dos trabalhadores. Quando possível influenciar os trabalhadores a pensar e agir de forma diferente, assim a mudança na cultura estará prestes a acontecer (STONER; FREEMAN, 1999). Ou seja, os gestores podem tentar influenciar os trabalhadores, mas nem sempre terão sucesso, depende dos valores dos trabalhadores inseridos no contexto da instituição.

No entanto, o mesmo autor destaca que nos estudos organizacionais, a cultura é percebida como algo que a organização tem, isto é, um processo passível de controle administrativo. Assim, cada organização possui uma cultura, mesmo que normalmente não seja formalizada, mas que todos os funcionário têm conhecimento e vivenciam no seu dia-adia. Cada empresa constrói uma cultura própria e cultiva no seu dia-a-dia, sendo que às vezes é tão peculiar que fica conhecida no mercado.

\section{RELAÇÃO DA MUDANÇA E CULTURA ORGANIZACIONAL}

Por algum tempo acreditou-se que as organizações deveriam buscar estabilidade a fim de conseguir o objetivo traçado. A estabilidade era sinônimo de controle organizacional e quanto mais controlada maior a probabilidade de se alcançar a eficácia organizacional. Porém há algum tempo se percebe que da mesma forma que o ambiente em que a organização está envolvida se modifica, a organização precisa seguir esta mesma tendência. Neste sentido, Luppi (1995) afirma que a mudança é literalmente forçada a uma organização pelo ambiente.

Atualmente as organizações estão envolvidas por um ambiente extremamente mutante e turbulento e isto se dá, devido a dois mecanismos gerais que se complementam: a globalização e a revolução científico-tecnológica. As implicações deste movimento global para as organizações são contundentes, afinal a organização como um sistema aberto, que interage com o meio em que está inserida, precisa se modificar para atender a este ambiente oferecendo assim novas oportunidades de negócio (DIAS, 2013).

Fatores do ambiente interno também são causadores de mudança, a literatura sobre mudança organizacional considera a natureza dual das mudanças: a preocupação com as mudanças na estrutura da empresa e a preocupação com as mudanças comportamentais, sejam do indivíduo ou de pequenos núcleos de pessoas. Portanto, os fatores internos ou externos que 


\section{CULTURA ORGANIZACIONAL E MUDANÇAS NA GESTÃO DA FACULDADE MUNICIPAL DE

determinam a mudança podem impactar nas diferentes realidades dos indivíduos (HALL, 2004).

O mudar significa não seguir sendo o mesmo, é o estado daquilo que evolui, do que se modifica. Neste contexto, o conceito de mudança organizacional está atrelado à introdução de novas formas de pensar, atuar e operar uma organização (DIAS, 2013).

A mudança organizacional pode ser definida como a alteração e a transformação da forma, a fim de que a organização possa sobreviver melhor ao ambiente. Percebe-se então a estreita relação existente entre mudança e ambiente (HALL, 2004).

O processo de mudança acontece seguindo um modelo sequencial de três passos em que a realidade das organizações é o equilíbrio quase estacionário entre as forças que propulsionam a mudança e as que a restringem, como um campo de forças. Neste modelo sequencial de três passos, o processo de mudança acontece em três distintos momentos: o descongelamento, a mudança e o recongelamento (LEWIN, 1989).

O descongelamento é a etapa em que o indivíduo se conscientiza de que a forma atual, seja de trabalho, de estrutura ou de valores, não suprem mais a necessidade e as objetivos propostos. Neste momento as velhas práticas são derretidas, abandonadas e desaprendidas e o sistema atual é colocado em cheque. O objetivo é quebrar os velhos paradigmas, inadequados para a realidade atual.

A segunda etapa do modelo é a introdução da mudança propriamente dita aparecendo um novo paradigma, em que novas ideias e práticas são identificadas e internalizadas. Nesta etapa, se estabelece novos valores, atitudes e comportamentos, reconhecendo novos paradigmas e assimilando e aceitando novos valores.

A última etapa do processo é a do recongelamento em que novas ideias e práticas são incorporadas definitivamente ao comportamento. Esta fase tem como objetivo consolidar a mudança de modo a fazer com que os colaboradores percebam os benefícios que este novo modelo traz. Esta etapa se refere à necessidade de reforçar o novo comportamento e o conjunto de cognições, produzindo dados confirmatórios (SCHEIN, 2009).

Aparentemente o processo de mudança parece simples, porém na medida em que as etapas vão sendo implementadas, Lewin (1989) relata a existência de um campo de força atuante que pode impedir ou propulsionar esta mudança. As forças positivas de apoio e suporte (forças motrizes) e as forças negativas (restrição), de oposição e resistência. 


\section{CULTURA ORGANIZACIONAL E MUDANÇAS NA GESTÃO DA FACULDADE MUNICIPAL DE

Neste sentido, as organizações podem ser vistas como um sistema em que a situação atual não é um padrão estático, mas sim um "equilíbrio" - ou "equilíbrio dinâmico" de forças trabalhando em direções opostas. Assim, qualquer mudança que pode ocorrer é resultante de uma mudança neste balanço ou equilíbrio onde as forças motrizes precisam ultrapassar e imobilizar forças. Ou seja, caso as forças de restrição atuem em maior grau não ocorrerá a mudança, mas caso as forças motrizes atuem de maneira a influenciar positivamente o indivíduo, a mudança ocorrerá.

Desta forma, para que a mudança se torne efetiva e menos traumática para a organização e seus membros, a sua implementação deve se dar de forma gradativa. Outra prática importante é participar os membros que deverão incorporar as mudanças no processo de planejamento. Sim, para mudar é preciso planejar e quanto mais os membros da organização estiverem engajados, mais facilmente ocorrerá o processo de mudança.

A cultura organizacional aparece como um aspecto fundamental no processo de mudança, pois apresenta crenças, valores fundamentais, que servem de referência em todas as tomadas de decisões na organização. A cultura organizacional é um produto dos valores dos fundadores, suas histórias e experiências coletivas. Desse modo, a cultura organizacional é parte fundamental de uma empresa e tem a tendência a resistir a mudanças (DIAS, 2013).

A cultura de uma organização pode ter interiorizado valores nos membros da organização que influenciarão sua forma de perceber o processo de mudança. Por exemplo, se uma organização tem incutida na sua cultura a valorização da inovação, os seus membros se sentirão menos inclinados a resistir aos processos de mudança que introduzam inovações do que indivíduos pertencentes a organizações com uma cultura menos progressista. No entanto, mesmo em organizações com culturas que valorizam a inovação, é possível encontrar indivíduos que resistirão às mudanças como uma forma de desafiar a cultura em si mesma ou como forma de se destacar politicamente.

Uma mudança profunda somente ocorre quando as pessoas percebem que seus pressupostos não são mais validados pela realidade. Neste sentido, na maior parte do tempo as mudanças ocorrem de forma incremental nas organizações, com decisões sendo tomadas sucessivamente em decorrência de eventos externos e internos (WOOD JR, 2000).

Para que a mudança se dê da forma mais natural possível, é importante planejá-la. Identificar a real necessidade, os envolvidos no processo de mudança para que seja 


\section{CULTURA ORGANIZACIONAL E MUDANÇAS NA GESTÃO DA FACULDADE MUNICIPAL DE

vislumbrada de que maneira ela ocorrerá. A dificuldade neste processo é identificar o padrão a ser trabalhado para produzir a mudança desejada (LUPPI, 1995).

Dias (2013) aponta quatro tipos de mudanças para a obtenção de vantagens estratégicas: a tecnológica, em produtos e serviços, de estratégia e estrutura e na cultura organizacional. $\mathrm{Na}$ mudança da cultura organizacional, este tipo de mudança refere-se a alteração de valores, atitudes, crenças e comportamentos dos membros da organização.

Frente a este cenário percebe-se que a mudança pode se dar em diferentes graus, variando entre as mudanças mais suaves até as mais bruscas. E que de alguma forma a mudança refletirá na organização como um todo, cabendo assim à organização conduzi-la da melhor forma possível de modo a agregar os seus participantes.

A modificação em determinados aspectos da cultura organizacional significa modificar ou reinterpretar os valores básicos, que estão profundamente integrados e que operam no nível inconsciente (DIAS, 2013).

O entendimento da cultura organizacional é primordial para o processo de mudança, pois a partir do conhecimento dos valores e crenças da organização é que as mudanças podem ser planejadas, considerando as premissas já incutidas nas pessoas. Portanto, a cultura organizacional pode representar um trunfo ou uma desvantagem neste processo, caso algumas crenças venham de encontro ao que deseja ser mudado, elas deverão ser trabalhadas com os membros da organização a fim de desvincular a identidade das pessoas a estas crenças específicas.

\section{CULTURA ORGANIZACIONAL NA INSTITUIÇÃO PÚBLICA}

$\mathrm{Na}$ observação da evolução do contexto da administração pública brasileira, especialmente das duas últimas décadas, percebe-se claramente as diversas alterações na forma de trabalho com que nossos gestores públicos vem enfrentando as dificuldades para gerir seus orçamentos e alcançar soluções paliativas ou definitivas às mais diversas demandas e exigências da sociedade.

Com isso, apesar das inúmeras adversidades encontradas nas organizações públicas, a demanda encontra-se nos esforços de transformar a cultura imposta as instituições desde o início da institucionalização do serviço público. De acordo com Guimarães (2000) será necessário para a administração pública deixar de lado as estruturas burocráticas que 


\section{CULTURA ORGANIZACIONAL E MUDANÇAS NA GESTÃO DA FACULDADE MUNICIPAL DE

engessam as instituições, buscando a transformação do setor público, trazendo inovações em busca de instituições flexíveis, dinâmicas e empreendedoras.

As instituições públicas na sua totalidade têm como objetivo proporcionar e garantir que os serviços prestados a sociedade sejam cumpridos na sua plenitude. Podendo assim ser vistos como modelos dinâmicos, excessivamente complexos, que envolvem muitas informações, dependem da estrutura da instituição, das pessoas envolvidas e das tecnologias disponíveis. As instituições públicas e seus prestadores de serviço desempenham suas atividades procurando cumprir com maior eficiência e produtividade a satisfação da sociedade (DIAS, 1998).

O problema mais perceptível na instituição pública é sem dúvida a substituição de trabalhadores a cada novo mandato, o que interfere na continuidade dos projetos e andamento de inovações administrativas, que estão ligadas a gestão pública. Essa descontinuidade administrativa é um dos pontos que diferenciam a instituição pública da privada, deixando evidentes algumas características do setor público, aplicadas à realidade brasileira, como projetos de curto prazo, duplicação de projetos, conflitos de objetivos e administração amadora (SCHALL, 1997).

Algumas situações em relação ao trabalhador público precisam ser revistas, principalmente em relação à estabilidade a todos os setores públicos, onde o entendimento dessa estabilidade causa a ineficiência, a desmotivação, a falta de disposição para o trabalho, já que não podem ser punidos com a demissão, implicando no aumento da ineficiência do servidor público. Outro ponto fundamental gerado pela estabilidade é o aumento dos custos públicos, que impede a adequação dos quadros de trabalhadores às reais necessidades do serviço, tanto em termos de quantidade quanto de especialização técnica, inviabilizando, ao mesmo tempo, a implantação de um sistema de administração eficiente, baseado em incentivos e punições (PEREIRA, 1996).

Alguns processos simples e dinâmicos na organização privada cujos objetivos são mais claros e necessitam de foco, tornam-se difíceis, complexos e lentos no setor público, onde teoricamente deveria ter o mesmo objetivo, por se tratar de instituição financiada pela sociedade. O controle público tem influência no planejamento e na gestão. Esse controle, de forte conotação política, é o único caminho para o equilíbrio das forças sociais. Nas organizações controladas pelo governo há a predominância dos processos políticos, que 


\section{CULTURA ORGANIZACIONAL E MUDANÇAS NA GESTÃO DA FACULDADE MUNICIPAL DE

muitas vezes oneram de várias formas os processos operacionais e administrativos ou, mesmo, se opõem a eles (JOHNSON, 1996).

Essas características, peculiares às organizações públicas, tornam-se um grande empecilho para a implantação de inovações tecnológicas, pois elas, em geral, são processos longos e que requerem um tempo de desenvolvimento e aperfeiçoamento, dificilmente restringindo-se a um único mandato governamental. Enfim pode-se dizer que as aspirações de meritocracia e competência técnica, discutidas entre os trabalhadores, certamente estará presente e rege as relações de trabalho em uma área envolvendo atividades de alta complexidade e técnica. O setor público é percebido como um terreno onde predominam o apadrinhamento político, as relações de favorecimento pessoal e os privilégios que contornam as normas formalmente instituídas. (PEREIRA, 1996).

A cultura organizacional da instituição de ensino influência e contribui para a formação da realidade. Compreende-la e explicá-la depende das possibilidades de elaboração, implantação e êxito dos programas de mudanças organizacionais em direção ao cumprimento de seus objetivos gerenciais e, consequentemente, sua missão institucional.

\section{ASPECTOS METODOLÓGICOS}

Apresentamos os procedimentos metodológicos que foram utilizados para o desenvolvimento do presente estudo, bem como fundamentá-los na percepção de diversos autores. O objetivo da análise contida no trabalho foi entender o fenômeno organizacional e o comportamento dos atores inseridos no contexto de uma instituição de educação superior da Grande Florianópolis.

Adotou-se, nesse estudo, o instrumento teórico sobre a ótica da diferenciação, uma vez que, entende-se a instituição enquanto composição de um encadeamento social, imbuída de comportamentos proativos, de cooperação e de conflitos (SAINSAULIEU; KIRSCHNER, 2006). Com base no cenário da diferenciação, se observa características como as percepções dos gestores das instituições e algumas particularidades culturais no interior da instituição estudada. Desta forma, percebe-se a instituição composta de diversidades culturais consideráveis entre os setores, o que denota a divergência da integração, que evidencia a defesa do argumento de haver uma instituição que possibilite dispor exclusivamente de uma cultura, forte e resistente. 


\section{CULTURA ORGANIZACIONAL E MUDANÇAS NA GESTÃO DA FACULDADE MUNICIPAL DE

A finalidade da pesquisa não é de solucionar problemas, contudo procura-se clarear o entendimento referente à constituição e os mecanismos sociais envolvendo cultura organizacional no âmbito da Faculdade Municipal de Palhoça. O estudo foi feito a partir da metodologia exploratória, onde o agente pesquisador interpreta a coleta de dados de cunho qualitativo. Do modo em que o assunto discute dimensões da cultura de uma instituição pública, se entende que apenas podem ser adotados métodos qualitativos. Todavia na conjuntura das ciências sociais, ou na sua grande maioria, há uma relutância em pesquisas dessa natureza que estudam esse tipo de método (DESLAURIERS; KÉRISIT, 2010).

A pesquisa se refere a um estudo de caso interpretativo em uma instituição pública municipal no qual foi aplicado o instrumento de entrevista com roteiro semiestruturado como técnica de coleta de dados, auferindo dados primários.

Para o desenvolvimento da pesquisa, foram utilizadas entrevistas com os coordenadores e gestores da instituição. Importante ponderar que neste tipo de pesquisa exploratória não se pode conjecturar com precisão os resultados que a própria pesquisa irá proporcionar. Desta forma, haverá ampla maleabilidade na seleção das questões e na própria condução das entrevistas, permitindo alterar ou modificar a condução das entrevistas a partir das respostas concedidas envolvendo as questões iniciais.

A pesquisa teve o intuito de adaptar as questões ao interesse do objeto de pesquisa. Assim, foram realizadas 7 (sete) entrevistas e optou-se por finalizar a coleta de dados com este número de entrevistados por considerar dispor de dados suficientes para as análises. Foi realizada na Faculdade Municipal de Palhoça, no período de outubro/2013 com os diretores, coordenadores de graduação e pós-graduação.

As entrevistas foram transcritas na sua totalidade, e sempre que mencionado na discussão dos dados, os entrevistados correspondentes são identificados E1, E2, E3, E4, E5, E6 e E7, omitindo a identificação de todos os gestores entrevistados. A informação de total discrição quanto a identidade dos entrevistados foi repassada aos mesmos antes de cada entrevista, isso para que não houvesse hesitação nas respostas e para que os entrevistados estivessem confiantes para responder as questões apresentadas.

A pesquisa foi realizada numa instituição de ensino superior, com sete anos de existência. Na instituição, há uma estrutura de três diretorias, três coordenações de graduação, uma coordenação geral de pós graduação, sete coordenações de pós graduação divididas por curso e demais cargos administrativos. Foram entrevistados três gestores da diretoria de alto 


\section{CULTURA ORGANIZACIONAL E MUDANÇAS NA GESTÃO DA FACULDADE MUNICIPAL DE

nível hierárquico, denominados diretora executiva, diretor acadêmico e diretor administrativo. Além dos três coordenadores da graduação e o coordenador geral da pós graduação.

A instituição está localizada na cidade de Palhoça - SC, onde estão todas as suas diretorias, coordenações e setores administrativos responsáveis pelas diretrizes da instituição, além da proximidade com a mantenedora, Prefeitura Municipal de Palhoça. A instituição é a única pública e gratuita no município, possui em torno de 1500 alunos na graduação e pós graduação, beneficiando principalmente moradores do município, disponibilizando $80 \%$ das vagas para alunos oriundos das escolas públicas de ensino médio residentes no município. Por fim, é relevante acrescentar que a instituição pesquisada tem um impacto social forte e fundamental para o desenvolvimento sócio e econômico do Município.

\section{RESULTADOS}

Será apresentada a análise dos dados levantados nas entrevistas, comparando-os com toda a teoria estudada sobre o tema. Com relação à probabilidade de gerenciamento da cultura organizacional, deve existir o entendimento visto que a cultura organizacional representa um padrão de conjecturas fundamentais partilhados pelos agentes que dispõe de mecanismos para mediar os problemas, internos e externos, empenhando-se de modo bastante aceitável. O conhecimento adquirido pode ser repassado aos novos agentes, moldando as pessoas à instituição em que trabalham. Os entrevistados E1 (2013) e E7 (2013) ressaltam a influência da mantenedora e da gestão atual.

De acordo com essa visão, legitima-se o conceito no qual a cultura de uma instituição seria gerenciada por líderes experientes em suas atividades como dirigentes, formadores de opiniões e representantes de convicções culturais. O conjunto organizacional de um grupo tem tradições e hereditariedade cultural em comum, ao processar-se no contexto no qual as pessoas inseridas, ou seja, no corpo social da organização descobrindo caminhos que levem a solução dos problemas e a vencer obstáculos, construindo entendimento sobre os hábitos adequados para que se possa compreender e resolve-los. Essas compreensões seriam disseminadas pelos agentes do corpo organizacional, que produzem representações, mitos e princípios para a ação, modificando-os em pensamentos involuntários (SCHEIN, 2009).

Para Aktouf (1994), os gestores tem influencia imediata no estabelecimento das categorias que afetam o arranjo da cultura organizacional. Alguns entrevistados, que da mesma maneira consideram a possibilidade de gerenciar a cultura, evidenciam a função dos 


\section{CULTURA ORGANIZACIONAL E MUDANÇAS NA GESTÃO DA FACULDADE MUNICIPAL DE

gerentes neste procedimento "dentro de uma instituição sempre a cultura vai ser influenciada, por bons gestores e por bons professores, quando se fala de instituição de educação" (informação verbal, E6, 2013).

A resposta do entrevistado E5 "Eu acho que a cultura da FMP é diretamente influenciada pela comunidade, pela mantenedora e pelos colaboradores e alunos. Sofre impacto desses sujeitos, dessas instituições que fazem parte", está de acordo com Fleury (2009), que pactua em partes com a teoria tutelada por demais autores, como Deal e Kennedy (1982) e Schein (2009) em relação à possibilidade de gerenciar a cultura.

Apesar da imparcialidade do tratamento teórico englobado ao gerenciamento ou não da cultura organizacional, ficou claro, com base nas entrevistas, que gerenciar ou modificar a cultura, embora seja factível, os obstáculos e as oposições, na percepção desses gestores, são muito grandes.

Apesar de não considerar a atividade setorial em que se atua, é necessário que os gestores da instituição encontrem-se propensos a se adequar as mudanças organizacionais. Todavia essas mudanças são designadas como inovações, uma crítica continua com as pessoas que não dão a importância relevante sobre elas, assim sendo, assumir um entendimento planejado e contar com agentes organizacionais aptos a se confrontar com as mesmas faz uma enorme diferença no universo competitivo, visto que o encadeamento dos processos de mudanças são normalmente lentos. Os entrevistados E1 (2013) e E7 (2013) acreditam que a atual gestão considera a cultura organizacional nos processos de mudança:

O estudo detalhado das mudanças deve ser mediado pela cultura organizacional, ou melhor, quanto mais notável e significativa for a casualidade da mudança para a estratégia, maior será a conciliação com a cultura da organização (SCHEIN, 2009).

Por meio do desenvolvimento do processo de aprendizagem sobre cultura organizacional e a percepção dos gestores defronte do estudo nos processos de mudanças, todos estão mais preocupados nos impactos da cultura nos resultados da instituição. Na instituição pesquisada a maioria dos entrevistados afirmam que a instituição considera a importância da cultura organizacional nos processos de mudança.

Sainsaulieu e Kirschner (2006) avaliam que a instituição encontra-se constantemente em processo de produção e propagação social, que não é um fato pronto, é transitório e está em constante mutação. No caso da instituição pesquisada envolve a comunidade e nesse sentido, para o entrevistado E5 (2013), “O impacto no processo de mudança é muito grande e 


\section{CULTURA ORGANIZACIONAL E MUDANÇAS NA GESTÃO DA FACULDADE MUNICIPAL DE

decisivo, tanto é que existe uma grande dificuldade em se fazer mudanças em função disso" (informação verbal, E5, 2013).

Outro entrevistado acredita que a instituição observa aspectos da cultura organizacional antes de efetuar ou propor mudanças. O entrevistado destaca que a atual gestão considera a cultura no processo de mudança, trazendo informações da mantenedora para discussão no grupo, ouvindo diversos pontos de vista (informação verbal, E4, 2013).

Dentro das instituições públicas, as inquietações com as mudanças abrangem e cobram precauções em relação aos níveis de resistência, especialmente pela eficiência de estimular os funcionários. Assim sendo, a atenção com as particularidades culturais podem ser consideradas até mesmo como parte da estratégia da instituição em questão, frente às ameaças que a organização fica sujeita ao fomentar mudanças sem a devida genuinidade e originalidade.

A cultura de uma organização suporta ampla interferência dos instituidores e líderes, porém, a contar de seu alicerçamento, as instituições sedimentam-se e perduram um sistema de condutas de comportamento exclusivo, produto das varias alternativas relativas à sua história. Conquanto, tal paradigma segue inerte, de maneira oposta, está em permanente transformação (FREITAS, 1991).

Instituições em processos de mudança analisam em particular os sintomas culturais, como o delineamento dos líderes, intercomunicação, políticas de gestão, coesão entre as habilidades, compromissos, obrigações, percepção da instituição e os comportamentos dos indivíduos, para conseguir realizar modificações com alguma margem de garantia (LIMA; ALBANO, 2002). Os entrevistados E1 (2013) e E7 (2013) observam esses fatores e ressaltam tais preocupações.

O entrevistado E3 (2013) acredita que a cultura organizacional impacta nos resultados da instituição, tanto nos resultados das atividades cotidianas como nos projetos de extensão focados na comunidade do município.

Para Morgan (1996), o que se faz coletivamente e individualmente compõe as organizações, tipificando-as como minisociedades. Nesse sentido, pode-se dizer que uma determinada ação realizada no âmbito da instituição, seja ela individual ou coletiva, tem reflexos em outras áreas da instituição. Nesse sentido, o entrevistado E4 (2013) considera que a cultura não afeta os procedimentos da instituição, mas que as ações individuais e coletivas, 


\section{CULTURA ORGANIZACIONAL E MUDANÇAS NA GESTÃO DA FACULDADE MUNICIPAL DE

em sua totalidade, levam à falta de comprometimento com os resultados desejados, mas que o resultado final é alcançado pela equipe.

Essa preocupação do entrevistado E4 (2013) refere-se aos processos de normatização para viabilizar as operações da instituição, mas, por outro lado, representa igualmente características dos estilos de gestão da instituição. O que também é a preocupação da entrevistada E5 (2013), principalmente quando a entrevistada ressalta aspectos de regras, normas e padronização. A busca do consenso parece estar presente na reflexão da entrevistada, ou seja, a entrevistada E5 (2013) admite divergência de interesses e até mesmo conflitos, mas percebe que são as pessoas que modelam a instituição.

A entrevistada E5 (2013) percebe a existência de interesses diferentes dentro da instituição pesquisada e acredita que a cultura, além de impactar nos resultados, também os compromete gestores e professores.

Essas mesmas preocupações estão presentes no depoimento seguinte. Friedberg (1995) manifesta que a presença de conjunto de indivíduos em hierarquias diversas de ligações de autoridade e poder caminham para a pluralidade de interesses e os impedimentos em alcançar a consonância e a concordância. $\mathrm{O}$ autor salienta que há a necessidade de modificar a cultura para que os propósitos da organização sejam atingidos, pois examina o desempenho da eficiência nas pessoas. O entrevistado E6 (2013), por sua vez, percebe o comportamento de acomodação, que também considera prejudicial para a instituição.

Para Schein (2009), a cultura é o recurso clássico de realizar as funções, compartilhadas por todos os componentes da instituição. Opondo-se à maioria dos entrevistados, o entrevistado E4 (2013) acredita que a maneira de trabalhar e os resultados da instituição não são afetados pela cultura: "não influencia muito, não impacta" (informação verbal, E4, 2013).

A reflexão do entrevistado E4 (2013) direciona a impossibilidade de os gestores conseguirem modificar a cultura de uma instituição, isto é hábitos, comportamentos e valores não são gerenciados, mas algo incorporado ao logo da tradição da instituição.

Incorporado à discussão teórica relacionando os elementos que envolvem a composição e a transformação da cultura organizacional, alguns autores indicam que as organizações que estão dentro na mesma localidade, funcionam no mesmo setor, dispostas com a mesma capacidade, entre outras especificidades em comum, ainda assim a cultura de cada instituição consiga ser divergente devido as suas particularidades. Para Lima e Albano 


\section{CULTURA ORGANIZACIONAL E MUDANÇAS NA GESTÃO DA FACULDADE MUNICIPAL DE

(2002), isso acontece pelo padrão de gestão professado por seus gestores e o perfil de liderança que impera intrinsicamente, o engajamento e empenho dos empregados, as convicções e as censuras, e as demais características mutáveis.

Entrevistados como E1 (2013) e E4 (2013) percebem fatores como a política do município como impactantes na cultura, por ser uma instituição pública municipal.

Assim como os entrevistados E1 (2013) e E4 (2013), o entrevistado E3 (2013) acredita, por sua vez, que o fator externo mais impactante é a mudança política que a mantenedora vem sofrendo nos últimos meses e os reflexos na própria sociedade. Para esse entrevistado, internamente o que mais impacta seria a consciência por uma cultura única, onde todos pensem da mesma forma e eventualmente, consigam provocar mudanças culturais.

Nesse mesmo contexto, o entrevistado E2 (2013) destaca que o que mais impacta na mudança da cultura da organização é o fator político, onde os cargos de direção estão diretamente vinculados ao prefeito e cada um tem seu modelo de gestão, podendo gerar a falta de continuidade nos trabalhos da instituição a cada mudança de mandato, principalmente o que envolve definições estratégicas, afetando os objetivos estabelecidos pela instituição como causa para não ocorrerem mudanças de cultura:

O entrevistado E5 (2013) ressalta a necessidade de estabelecer compromissos assumidos internamente, inserindo processos documentais que possam garantir a instituição, “O alinhamento documental que precisa se seguir, o que é de lei, que nos garante, que nos permite. E atitudinal" (informação verbal, E5, 2013).

Os entrevistados E6 (2013) e E7 (2013) acreditam que o que mais impacta na mudança da cultura são os valores individuais trazidos para instituição.

No processo de mudança, a instituição absorve fundamentos endógenos e exógenos que causam tensão, para os quais a instituição obtém as possibilidades de respostas. Para Morgan (1996), a instituição está contextualizada em um ambiente cultural e universal e é neste ambiente que se avalia como a instituição será dirigida. Cada instituição é influenciada pelo meio cultural onde está inserida.

Para os entrevistados E1 (2013) e E7 (2013), não há alternativas para a instituição, já que todos os recursos da instituição são disponibilizados pela Prefeitura Municipal de Palhoça, diante das imposições, a cultura também é afetada, como se pode perceber abaixo:

Nesse sentido, o entrevistado E5 (2013) destaca a resistência gerada internamente diante das mudanças impostas pela mantenedora, para o entrevistado há ruptura nos processos 


\section{CULTURA ORGANIZACIONAL E MUDANÇAS NA GESTÃO DA FACULDADE MUNICIPAL DE

e dificuldade de aceitação em função de cargos políticos e indicações para trabalhar na instituição.

Para os entrevistados E4 (2013) e E6 (2013), por outro lado, a cultura é afetada pelas mudanças impostas pela mantenedora, contudo, igualmente por meio dos mecanismos de trabalho. Para o entrevistado, o embate está na tensão imposta produzida sob o trabalho, sempre evitando a aplicação de penalidades.

Os entrevistados E2 (2013) e E3 (2013) reforçam a grande influência da mantenedora inclusive em função do orçamento anual disponibilizado para instituição e por outro lado o retorno gerado pela instituição com os resultados para o município.

Em um ambiente de mudança organizacional, resistência a essas mudanças sucedem com regularidade. Para Dias (2013), a oposição pode ser individual ou coletiva.

$\mathrm{Na}$ instituição pesquisada, corroborando com os autores, alguns entrevistados, identificam tanto a resistência individual quanto a coletiva dentro da instituição.

Para o entrevistado E2 (2013), a resistência é mais forte no individual e está relacionada ao comodismo, mas também existe no coletivo.

Contrariando o entrevistado anterior, o entrevistado E4 (2013), analisa que a resistência é mais forte coletivamente, relacionando com a zona de conforto dos indivíduos.

Já os entrevistados E1 (2013), E3 (2013) e E5 (2013) percebem tais resistências, tanto em nível individual como coletivo.

Os entrevistados E6 (2013) e E7 (2013) declaram que existe a resistência porque a instituição exibe uma cultura arraigada de "empresa pública". Para os entrevistados, por sua vez, a resistência ocorre porque os indivíduos relacionam aspectos políticos e interesses pessoais.

As mudanças culturais necessitam bastante do nível de receptividade ou de oposição dos agentes de uma instituição. Os funcionários diversas vezes se opõem a mudança proposta, mas não sustentam pelo motivo de que quem possui a capacidade e o poder de implantar as modificações é a diretoria.

No item resistência a mudança, os entrevistados responderam duas perguntas, a primeira já analisada e a segunda em relação há modificar hábitos e comportamentos.

Toda instituição que inicia o processo de mudança, tende na realidade a moldar condutas e posturas, impostas pelo ambiente, além de transformar comportamentos e atitudes, o que só é possível transformando as crenças e os valores que influenciam. 


\section{CULTURA ORGANIZACIONAL E MUDANÇAS NA GESTÃO DA FACULDADE MUNICIPAL DE

Os entrevistados E1 (2013) e E4 (2013) acreditam ser muito complicado modificar hábitos e comportamentos dos profissionais envolvidos na instituição.

Para atingir alguns propósitos, não adianta apenas querer mudar, a instituição precisa saber o que fazer, tendo o diagnostico real das necessidades de mudança, considerando o desenvolvimento da instituição no todo.

Os entrevistados E2 (2013), E3 (2013), E5 (2013) e E7 (2013) acreditam ser possível modificar alguns hábitos e comportamentos dentro da instituição.

Entender o processo de mudança cultural é primordial para uma melhor gestão dessas transformações, criando condições para a mudança do modelo mental e para o alcance dos resultados institucionais.

\section{CONCLUSÃO}

Ao realizar esta pesquisa sobre cultura organizacional junto a Faculdade Municipal de Palhoça, buscamos analisar como os gestores públicos manifestam suas percepções envolvendo valores, aspectos comportamentais e políticas públicas.

Um debate teórico a cerca do objeto cultura organizacional investiga se esta é capaz ou não de ser gerenciada. Na pesquisa realizada, os entrevistados creem ser factível gerenciar a cultura organizacional, uma vez que a instituição pesquisada é muito influenciada pela mantenedora.

Ao se examinar os processos de mudança na instituição, verifica-se que a atual gestão considera a cultura organizacional nos processos de mudança. Todos os agentes envolvidos buscam adaptar-se a cultura da instituição, mas a maioria traz consigo as experiências acumuladas de outras instituições, com seus métodos de trabalho, a sua cultura em si, particularidades que impactam no processo de mudança. Acredita-se que poucos dos agentes envolvidos realmente tem interesse em adaptar-se a cultura da instituição, não sendo a FMP a instituição mais importante e por envolver processos políticos.

Assim, com a perspectiva da diferenciação empregada no atual estudo, na instituição pesquisada, verifica-se a presença de inúmeras subculturas, que levam em conta as heterogeneidades constatadas e relatadas nas declarações dos gestores. Em suma, os gestores da instituição são inovadores e dinâmicos em toda a existência da instituição, facultando a circunstância de uma cultura em constante movimentação. 


\section{CULTURA ORGANIZACIONAL E MUDANÇAS NA GESTÃO DA FACULDADE MUNICIPAL DE

Assim sendo, na atual pesquisa, mediante as entrevistas realizadas, se consegue ponderar que, na instituição pesquisada, a ótica da diferenciação oportunizou assimilar como essas subculturas se manifestam, uma vez que os entrevistados deixaram aparentes diferentes perspectivas a cerca da mesma instituição. Entretanto, é relevante ressaltar, que a despeito de haver inúmeras culturas no interior da instituição, uma fração dos entrevistados acredita na possibilidade de unificar a cultura, em conformidade do trabalho oriundo da alta administração, correlacionando propósitos, diretrizes e conduta pública comum a todos.

Em suma, deduz-se que com o transcorrer deste estudo, o desenvolvimento gradativo do mesmo e os processos de mudança englobam inúmeros debates e criação de novos princípios e valores para a instituição. Apesar disso, estes princípios, padrões, atitudes e praticas não são incorporadas pelos funcionários da instituição, uma vez que não existem mecanismos para que se faça isso acontecer. De qualquer maneira, existe um movimento na instituição que, hipoteticamente, apresentam a finalidade de disseminar e instituir processos que levem grande parte da instituição a internalizar princípios acordados, contudo na fala dos entrevistados, é fundamental um processo de trabalho com condutas mais dinâmicas e realizáveis. Como participante da pesquisa, verifica-se que não existe por parte dos professores um empenho para que os processos funcionem de forma adequada na instituição, a visão do "público" fica impregnada na mentalidade da grande maioria dos docentes, deixando tudo como está para não se ter trabalho.

Conforme as informações dadas pelos entrevistados, há inúmeros elementos que causam impacto nas mudanças que verificamos na instituição pesquisada. Como trata-se de uma instituição pública municipal os elementos externos manifestam grande domínio sobre o seu contexto e, portanto, sobre a sua cultura. A mantenedora impacta diretamente nas estratégias e conduta da instituição pesquisada, gerando inicialmente muita resistência por parte dos empregados. Este é um ponto muito delicado e que gera muita resistência, pois em muitas ocasiões a instituição deixa de realizar alguma estratégia de mudança e se obriga a tomar atitudes políticas impostas pela mantenedora.

Constatamos, em determinados instantes, que o sistema de tomada de decisão é interativo e participante, conforme o modelo de gestão da instituição. $\mathrm{Na}$ instituição, não existe uma política que estabeleça o padrão de conduta de como deve se efetivar os 


\section{CULTURA ORGANIZACIONAL E MUDANÇAS NA GESTÃO DA FACULDADE MUNICIPAL DE

procedimentos nos processos decisórios nos setor de domínio e o comportamento dos gestores em relação a essa cooperação dos funcionários.

As entrevistas foram feitas exclusivamente com os gestores, instrumento central da pesquisa, já que os mesmos são encarregados dos processos decisórios. Assim, verificamos as vulnerabilidades da pesquisa. Deste modo, recomendamos para posteriores pesquisas dentro desse tema, aumentar a quantidade de entrevistados, objetivando apurar mais o estudo a ser realizado, diversificando o corpo gerencial, e abrangendo a pesquisa aos demais funcionários que não desempenhem funções gerenciais, o que engrandece a discussão ao qual o estudo se propõe. Nesta ocasião foi proposital realizar a pesquisa somente com gestores em função de todo o movimento político que envolve a mantenedora, onde passamos o ano 2013 com várias alterações de prefeito no Município de Palhoça, trazendo certa instabilidade a instituição, sendo impossível fazer um planejamento adequado, onde se depende de verba da mantenedora.

Isto posto, evidenciamos que as percepções foram de qualquer forma satisfatórias para investigar as argumentações e os desacordos que englobam o contexto de uma instituição, em que são debatidos temas que relacionam a conduta social e comportamento dos mesmos no dia a dia da instituição.

Assim, se coloca em evidencia a influencia para pesquisadores que almejam dar sequencia a esse estudo objetivando a análise em cultura organizacional. Acreditamos que várias instituições, como a Faculdade Municipal de Palhoça, inclusive em outros setores, atravessam circunstâncias parecidas quando se debate diferentes tipos de liderança, antagonismos culturais, valores, princípios ideológicos, e sobretudo as pessoas situadas no contexto institucional pesquisado. Para finalizar, ante todas as ações observadas, é importante ressaltar que mesmo as pequenas ações produzem possíveis mudanças a todos que participam dos processos da instituição.

\section{REFERÊNCIAS}

AKTOUF, O. O Simbolismo e a Cultura de Empresa: dos abusos conceituais às lições empíricas . In:CHANLAT, J.F.- O Indivíduo na Organização - dimensões esquecidas. Vol. II. São Paulo: Atlas, 1994.

DEAL, T. E.; KENNEDY, A. A. Corporate cultures : the rites and rituals of corporate life. Reading,MA : Addison-Wesley, 1982. 
DESLAURIERS, Jean-Pierre; KÉRISIT, Michele. O delineamento da pesquisa qualitativa. In: POUPART, Jean et al. A pesquisa qualitativa. Enfoques epistemológicos e metodológicos. Petrópolis, RJ: Vozes, 2010. p. 127-153.

DIAS, Reinaldo. Cultura organizacional: construção, consolidação e mudanças. São Paulo: Atlas, 2013.

DIAS, T. L. Modelo de sistemas viáveis em organizações públicas: um estudo de caso da função de planejamento de informações estratégicas para informatização da Secretaria Municipal de Saúde de Belo Horizonte. 1998, 146 f. Dissertação Mestrado, Escola de Governo, Fundação João Pinheiro, Belo Horizonte, 1998.

DUBRIN, A. J. Fundamentos de Comportamento Organizacional. São Paulo: Pioneira Thomson Learning, 2006.

FIORELLI, J.O. Psicología para Administradores. São Paulo: Atlas, 2000.

FLEURY, M. T. L. Organizational Culture and the Renewal of Competences, BAR. Brazilian Administration Review, v.6, p. 1-14, 2009.

FREITAS, Maria Ester de. Cultura organizacional: formação, tipologias e impacto. 1 ed. São Paulo: Makron, 1991.

FREITAS, Maria Ester de. Cultura organizacional. 2 ed. Rio de Janeiro: FGV, 2000.

FREITAS, Maria Ester de. Cultura organizacional e crítica. São Paulo: Thomson Learning, 2007.

FRIEDBERG, E. O poder e a regra: dinâmicas da acção organizada. Lisboa: Instituto Piaget, 1995.

GUIMARÃES, T. A. A nova administração pública e a abordagem da competência. Revista de Administração Pública, Rio de Janeiro, v. 34, n. 3, p. 125-140, maio/jun. 2000.

HALL, Richard H. Organizações: estruturas, processos e resultados. São Paulo: Prentice Hall, 2004.

HOFSTEDE, Geert. Identifying Organizational Subcultures: An Empirical Approach. Journal of Management Studies. Volume 35, Issue 1, pages 1-12, January, 1998.

JAIME JÚNIOR, Pedro. Um texto, múltiplas interpretações: antropologia hermenêutica e cultura organizacional. Revista de Administração de Empresas - RAE. v. 42, n. 4. out./nov./dez. 2002, p. 72- 83 .

JOHNSON, B. B. Serviços públicos no Brasil: mudanças e perspectivas. São Paulo: Edgard Blucher, 1996. 
LACOMBE, Francisco José. Recursos Humanos: princípios e tendências. São Paulo, Editora Saraiva, 2005.

LEWIN, Kurt. Problema de dinâmica de grupo. São Paulo: Cultrix, 1989.

LIMA, Súsi M. Barcelos e; ALBANO, Adriana Gaffrée Burns Albano. Um estudo sobre Clima e Cultura Organizacional na concepção de diferentes autores. Rev. CCEI URCAMP, Ago. 2002. Disponível em: <http://www.facape.br/ruth/adm- 13 comport_organ/Conceito_de_cultura_e_clima_organizacional.pdf

LUPPI, Galvani. Cultura organizacional: passos para a mudança. Belo Horizonte: Luzazul Editorial, 1995.

LUZ, Ricardo. Gestão de clima organizacional. Rio de Janeiro: Qualitymark, 2003.

MORGAN, Gareth. Imagens da organização. São Paulo: Atlas, 1996.

PEREIRA, L. C. B. Da administração pública burocrática à gerencial. Revista do Serviço Público, v. 120, n. 1, p. 7-40, jan./abr. 1996.

PIRES, J. C. S.; MACÊDO, K. B. Cultura organizacional em organizações públicas no Brasil. Revista de Administração Pública, Rio de Janeiro, v. 40, n. 1, p. 81-105, jan.-fev. 2006.

SAINSAULIEU, Renaud; KIRSCHNER, Ana Maria. Socilogia da empresa. Organização, poder, cultura e desenvolvimento no Brasil. Rio de Janeiro: DP\&A, 2006.

SCHALL, E. Public sector succession: a strategic approach to sustaining innovation. Public Administration Review, Washington, D.C., v. 57, n. 1, p. 4-10, jan./fev. 1997.

SCHEIN, Edgar H. Cultura organizacional e liderança. São Paulo: Atlas, 2009.

SCHERMERHORN JR., John R. Administração. 5. ed. Rio de Janeiro: LTC, 1999.

SILVA, Narbal; ZANELLI, José Carlos. Cultura Organizacional. In: ZANELLI, J.C; BORGES-ANDRADE, J.E; BASTOS, A.V.C. Psicologia, organizações e trabalho no Brasil. Porto Alegre: ARTMED, 2004, p.407-442.

STONER, J. A. F.; FREEMAN, R. E. Administração. Rio de Janeiro: LTC, 1999.

ZANELLI, José Carlos; BORGES-ANDRADE, Jairo Eduardo; BASTOS, Antonio Virgílio Bittencourt. Psicologia, organizações e trabalho no Brasil. Porto Alegre: Artmed, 2004.

WOOD Jr, Thomaz. Mudança organizacional. São Paulo: Atlas, 2000. 